Article

\title{
Bone Healing and Regeneration Potential in Rabbit Cortical Defects Using an Innovative Bioceramic Bone Graft Substitute
}

\author{
Keng-Liang Ou ${ }^{1,2,3,4} \oplus$, Ping-Jen Hou ${ }^{5,+}$, Bai-Hung Huang ${ }^{6,7,8}$, Hsin-Hua Chou ${ }^{9,10}$, \\ Tzu-Sen Yang 5,11,12, Chiung-Fang Huang ${ }^{13,14, *}$ and Takaaki Ueno ${ }^{15, *}$ \\ 1 Department of Dentistry, Taipei Medical University-Shuang Ho Hospital, New Taipei City 235, Taiwan; \\ klouyu@gmail.com \\ 2 Department of Oral Hygiene Care, Ching Kuo Institute of Management and Health, Keelung 203, Taiwan \\ 3 Health Sciences University of Hokkaido, Ishikari-gun 061-0293, Japan \\ 4 3D Global Biotech Inc. (Spin-off Company from Taipei Medical University), New Taipei City 221, Taiwan \\ 5 Graduate Institute of Biomedical Materials and Tissue Engineering, College of Biomedical Engineering, \\ Taipei Medical University, Taipei 110, Taiwan; kkinghot@gmail.com (P.-J.H.); tsyang@tmu.edu.tw (T.-S.Y.) \\ 6 Biomedical Technology R \& D Center, China Medical University Hospital, Taichung 404, Taiwan; \\ babyfireh@gmail.com \\ 7 Asia Pacific Laser Institute, New Taipei City 220, Taiwan \\ 8 Implant Academy of Minimally Invasive Dentistry, Taipei 106, Taiwan \\ 9 School of Dentistry, College of Oral Medicine, Taipei Medical University, Taipei 110, Taiwan; \\ hhchou@tmu.edu.tw \\ 10 Dental Department of Wan-Fang Hospital, Taipei Medical University, Taipei 116, Taiwan \\ 11 School of Biomedical Engineering, College of Oral Medicine, Taipei Medical University, Taipei 110, Taiwan \\ 12 Graduate Institute of Nanomedicine and Medical Engineering, Taipei Medical University, Taipei 110, Taiwan \\ 13 School of Dental Technology, College of Oral Medicine, Taipei Medical University, Taipei 110, Taiwan \\ 14 Department of Dentistry, Taipei Medical University Hospital, Taipei 110, Taiwan \\ 15 Department of Dentistry and Oral Surgery, Osaka Medical College, Osaka 569-8686, Japan \\ * Correspondence: chiung0102@tmu.edu.tw (C.-F.H.); ueno@osaka-med.ac.jp (T.U.) \\ + Co-first author: Ping-Jen Hou.
}

Received: 14 July 2020; Accepted: 4 September 2020; Published: 8 September 2020; Corrected: 4 January 2022

\begin{abstract}
This study aimed to elucidate the local effect and micro-computed tomographic ( $\mu$-CT) assessment following bone implantation of an innovative bioceramic ( $\alpha$-calcium sulfate hemihydrate; $\alpha-\mathrm{CSH}$ ) on femur lateral condyle cortical bone of rabbit models. The innovative $\alpha$-CSH bioceramic was synthesized through a green processing technology (microwave irradiation treatment). The bilateral implantation model was performed among $24 \mathrm{New}$ Zealand White rabbits which were divided into three groups based on the type of filling materials: $\alpha-\mathrm{CSH}$, control, and blank. Treatments were performed in defects with $6 \mathrm{~mm}$ diameter and $7 \mathrm{~mm}$ depth and observed after 2, 4, 8, and 12 weeks. Material reaction and bone formation after implantation were evaluated radiographically and histopathologically. The $\mu-\mathrm{CT}$ analysis results showed that the degradation of $\alpha-\mathrm{CSH}$ and control material was similar at 4 and 8 weeks. The bone volume in the defects indicated the $\alpha$-CSH increased most in 8 weeks. In histopathological evaluation, the $\alpha$-CSH group was repaired with lamellar bone and well-grown bone marrow infiltration similar to the control material. Moreover, the $\alpha$-CSH revealed a faster degradation rate and better healing progress than the control material under the same conditions. Therefore, the $\alpha$-CSH was confirmed to be useful in promoting osteoconduction and in controlling the resorption rate in bone defects. Further, the innovative $\alpha$-CSH could be considered as a promising bone substitute for utilization in bone reconstructive therapy in dental and orthopedic fields.
\end{abstract}


Keywords: calcium sulfate hemihydrate; bioceramic; bone defect; bone graft substitute; bone regeneration

\section{Introduction}

Bone defect is defined by the lack of bone tissue in the specific part of the body that may emerge as a result of injury, infection, inflammation, congenital, or traumatic processes [1-3]. In some cases, it can also occur as a consequence of ongoing diseases or surgical procedures $[4,5]$. When the regeneration process in bone loss is hampered or even stopped, bone reconstruction via surgical implantation of materials is often required to increase bone regeneration [6-8]. During recent decades, materials used for bone reconstruction have mostly been acquired from autograft materials owing to their superior bone conduction, inducibility, and osteogenesis $[9,10]$. In terms of bone healing, an autologous bone graft remains the treatment of choice in clinical practice [11,12]. However, complications related to the harvesting procedure and the limited quantity of donor bone confine the clinical application of this technique [13-15]. Due to this fact, the necessity of other bone substitutes as alternative graft materials is indispensable for successful bone reconstructions [16-18].

An ideal bone substitute should satisfy criteria such as being osteoinductive, osteoconductive, and bioresorbable [13-15]. It should also not have any risk of immunological rejection and should be thermally nonconductive $[3,5,11]$. In recent years, a number of alloplastic materials for new bone substitutes such as ceramic and ceramic composites, hydroxyapatite, tri-calcium phosphate, calcium phosphate cement, calcium sulfate, and bone morphogenetic protein have been extensively studied $[9,11,19,20]$. Although there is no material to completely replace autologous bone, an outstanding bone substitute, $\alpha$-calcium sulfate hemihydrate $(\alpha-\mathrm{CSH})$, can be used instead of autologous bone grafts thanks to its excellent biocompatibility, osteoconductivity, easy availability, and biodegradability $[2,4,9]$. The $\alpha-\mathrm{CSH}$ is regarded as a prime type of bone substitute that plays a crucial role in bone formation by facilitating the ingrowth of bone $[13,21,22]$. A growing body of evidence indicates that $\alpha$-CSH has been clinically used to treat various bone defects like resorbed maxilla [23,24], post extraction-socket preservation [25,26], and large segmental bone defect [21] due to its similar properties to the autologous bone. For this reason, the biomedical field is showing a vast interest in the development of $\alpha$-CSH as a potential booster for bone regeneration $[19,27]$. While this bone substitute has shown superior biological properties, there remains a need to improve the performance of the current $\alpha$-CSH for clinical practice $[2,13,28]$.

In our previous study, we developed an innovative $\alpha$-CSH bioceramic synthesized from green processing technology (microwave-irradiation treatment) with superior blood wettability and biocompatibility [27]. Histopathological evaluation from an in vivo test of chick chorioallantoic membrane confirmed that the innovative $\alpha$-CSH bioceramic not only induces angiogenesis formation but also enables osteogenesis potential [27]. In the present study, we further use the innovative $\alpha$-CSH bioceramic as a bone graft substitute in artificially-created defects of rabbit models to analyze new bone formation and material degradation. It is believed that the innovative $\alpha$-CSH bioceramic possesses the ability to regenerate a new bone with good in vivo biocompatibility for clinical applications especially for bone repair and reconstruction in dental and orthopedic fields.

\section{Materials and Methods}

\subsection{Materials}

The high-purity $\alpha$-CSH bioceramic $\left(\mathrm{CaSO}_{4} \cdot 0.5 \mathrm{H}_{2} \mathrm{O}\right)$ was synthesized with a microwave-irradiation technique as in our previously-reported study [25], while the control material was obtained from the medical-grade $\alpha$-CSH bone graft substitute (Merries Uni-Osteo, J.O. Corporation, New Taipei City, Taiwan). The morphology and particle size of the implanted materials are shown in Figure 1. 


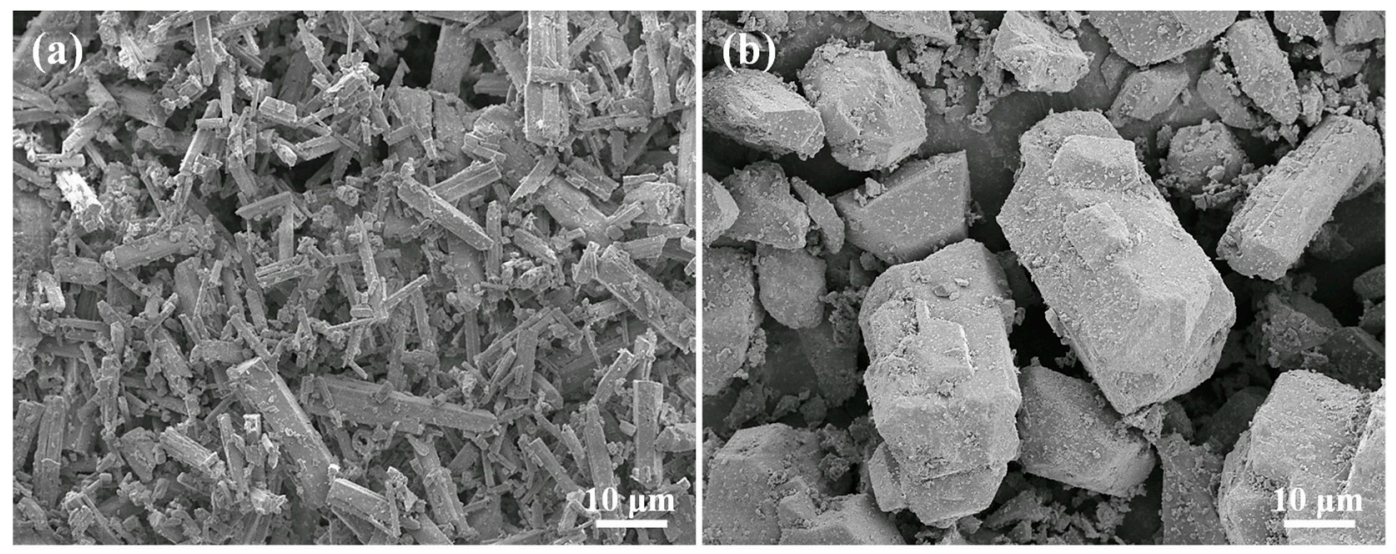

Figure 1. Electron microscope images of the implanted materials: (a) innovative $\alpha$-calcium sulfate hemihydrate $(\alpha-\mathrm{CSH})$ had uniform short column crystals around $10 \mu \mathrm{m}$ in length and (b) control $\alpha$-CSH exhibited large and long column crystals around $50 \mu \mathrm{m}$ in length.

\subsection{Study Design}

The present in vivo study was conducted at Lepto Biotech Co., Ltd. (Taipei, Taiwan) according to the concept of ISO 10993-6: 2007 "Biological evaluation of medical devices-Part 6: Tests for local effects after implantation". Twenty-four New Zealand White (NZW) rabbits procured from the Livestock Research Institute (Tainan, Taiwan) were included in the current prospective controlled study. The NZW rabbits were divided into three groups based on the type of filling materials namely $\alpha$-CSH group, control group, and blank group. The healing of defects were observed at 2, 4, 8, and 12 weeks post-treatment.

\subsection{Implantation Procedure}

General anesthesia was induced by xylazine and Zoletil 50 and maintained by isoflurane via inhalation. The procedure was performed under sterile aseptic conditions. The bilateral implantation was performed among $24 \mathrm{NZW}$ rabbits in $6 \mathrm{~mm}$ diameter and $7 \mathrm{~mm}$ depth artificially-created defects. The $\alpha-\operatorname{CSH}(\mathrm{n}=4)$ and control material $(\mathrm{n}=4)$ were randomly implanted in the animal's left or right femur lateral condyle cortical bone after defect drilling; in the blank group $(n=4)$, the created defects were left unfilled. The materials were implanted as a powder with approximately $0.2 \mathrm{~g}$ of material added in each defect. The healing process and bone formation was observed at each time point $(2,4,8$, and 12 weeks). After the specified observational period, animals were also sacrificed and subjected to histological evaluation.

\subsection{Micro-Computed Tomographic ( $\mu-C T)$ Evaluation}

Samples were scanned using Bruker Skyscan 1176 (Kontich, Belgium) at $18 \mu \mathrm{m}$ resolution. The $\mu$-CT scanning was carried out at $80 \mathrm{kV}$ of voltage, $300 \mu \mathrm{A}$ of current, and $400 \mathrm{~ms}$ of exposure time and with a (copper + aluminum) filter. The reconstruction of sections was performed using GPU-based scanner software (NRecon). The region of interest (ROI) was defined the bone area $1 \mathrm{~mm}$ from the edge of femur lateral condyle cortical bone. The implanted cylinder, with a diameter of $7 \mathrm{~mm}$ and a depth of $3 \mathrm{~mm}$, was chosen as the ROI. The Bruker software package (CTAn, version v.1.18) was utilized to calculate morphometric indices or bone mineral density $\left(\mathrm{BMD}, \mathrm{g} / \mathrm{cm}^{3}\right)$ of bone, while the BMD calibration phantoms $\left(0.25\right.$ and $0.75 \mathrm{~g} / \mathrm{cm}^{3}$ hydroxyapatite) were used to validate the density control. For exemplification, volume-rendering software, CTVox, was adopted to create the three-dimensional image. New bone volume (BV/TV, \%) was the percentage of newly-formed bone volume in the ROI, in which BV was the volume of the new bone formation and TV was the total volume of the ROI. Moreover, the ratio between the volume of the residual material and the total volume of the materials 
within the ROI in each defect site was calculated as the residual material volume of the residual fraction (RMVF, \%). This calculation was able to examine the degradation rate of the material. The RMVF was equal to bone volume per trabecular volume $(\mathrm{VV} / \mathrm{TV}, \%)$ in which TV represented the total volume of the material and VV represented the volume of the residual material.

\subsection{Histopathological Analysis}

Following euthanasia, femurs with defects and implants were retrieved and fixed in $10 \%$ neutral-buffered formalin. After the serial procedure of decalcification, trimming, tissue processing, sectioning, and embedding, the paraffin-embedded sections were stained with hematoxylin and eosin (H\&E) and observed microscopically using an Aperio CS digital image capture pathology scanner (Leica Biosystems, Buffalo Grove, IL, USA) under different magnifications.

\subsection{Statistical Analysis}

Microsoft Excel 2016 version was used to carry out the statistical analysis. The post-hoc Tukey HSD (Honestly Significant Difference) was used for multiplicity of contrasts with $p<0.05$ considered as the level of significance. The value of each variable from the multiple readings was presented as mean \pm standard deviation.

\section{Results and Discussion}

\subsection{Bone Healing Features of the Implanted Materials}

Figure 2 depicts the $\mu$-CT images of the surgical area as well as the healing of bone defects at each time point. As the results show, the blank group (Figure 2a) demonstrated some new bone formation within the defects, but to a lesser degree than that observed in the control material (Figure 2b) and the $\alpha$-CSH (Figure 2c). New bone was more rapidly formed in the $\alpha$-CSH group (Figure 2c) compared to the blank group (Figure 2a). Overall, there was not much difference in the newly-formed bone between the $\alpha$-CSH group (Figure 2c) and the control group (Figure 2b). However, when we looked into the progress of bone healing from time to time, the sites implanted with $\alpha-\mathrm{CSH}$ demonstrated a tendency to have better progress of tissue remodeling in the defect area. In this study, the innovative $\alpha$-CSH was prepared through the microwave-irradiation treatment since it possesses several pros over the commercially-available medical-grade $\alpha-\mathrm{CSH}$ (mostly fabricated by the traditional dehydration method) in terms of purity control $[27,29]$. The dehydration method is prone to creating certain impurities like $\beta$-calcium sulfate hemihydrate and anhydrite as the byproduct since this method is unable to control the variations in temperature and pressure [30]. These impurities will affect the crystal size and morphology with elongated crystals that eventually reduce the mechanical and biological properties $[31,32]$. On the other hand, the microwave-irradiation treatment can synthesize high-purity bone graft substitute without sacrificing any useful mechanical or biological properties with controllable temperature and pressure, a great heating rate, and a homogeneous reaction temperature of volume [33]. Besides, this method resulted in $\alpha$-CSH with uniform short column crystals (approximately $10 \mu \mathrm{m}$ in length) that can render high hydrophilic properties for setting in the dehydrated state [27]. It is known that the crystal size and crystalline structure influence the setting characteristics of bone graft materials $[34,35]$, while the water absorption ability and setting time of material influence the number of proteins and growth factors absorbed in the blood which in turn affect osteoconduction, angiogenesis, and bone regeneration after the implantation [36]. 
(a)

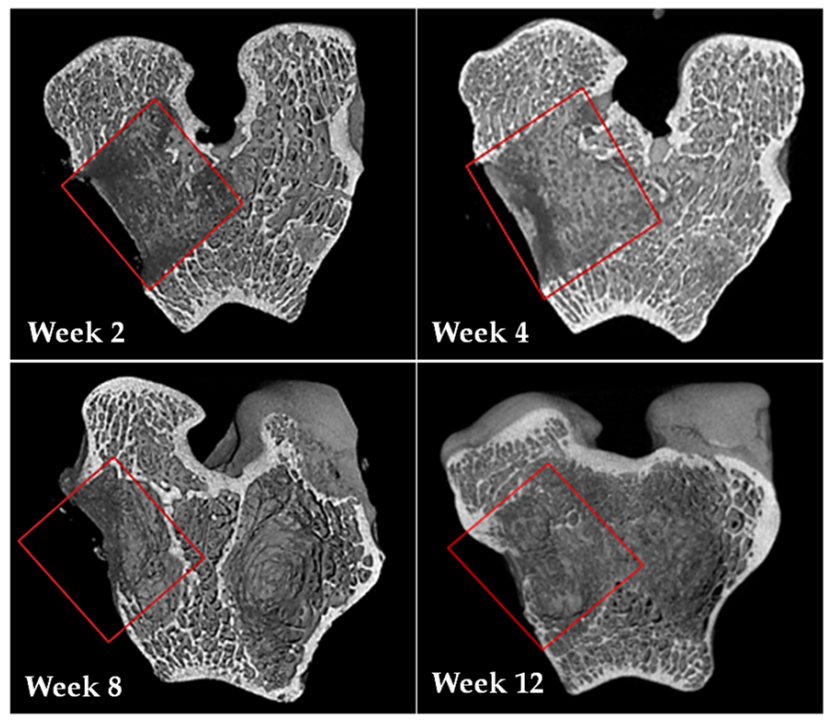

(b)

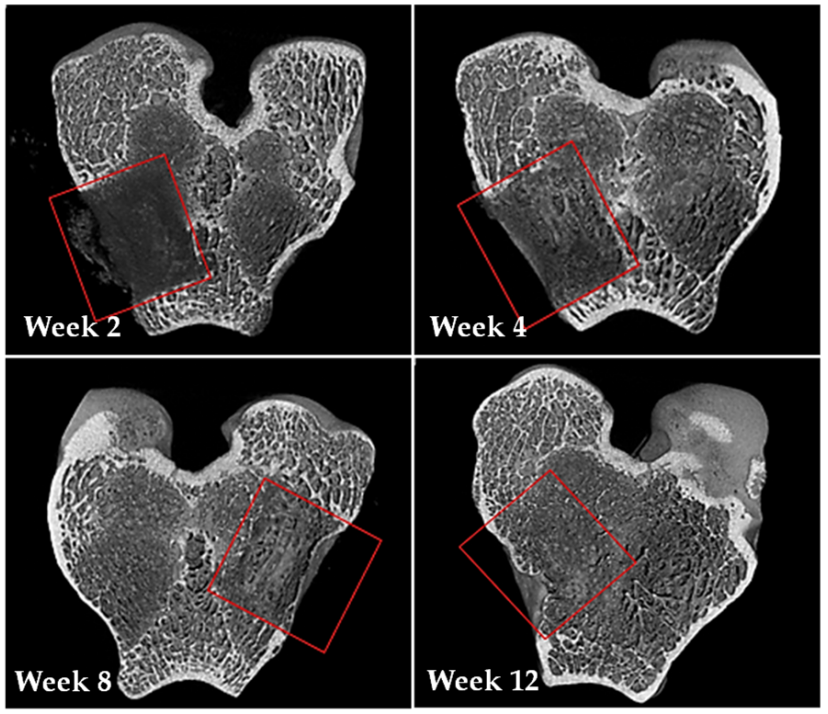

(c)
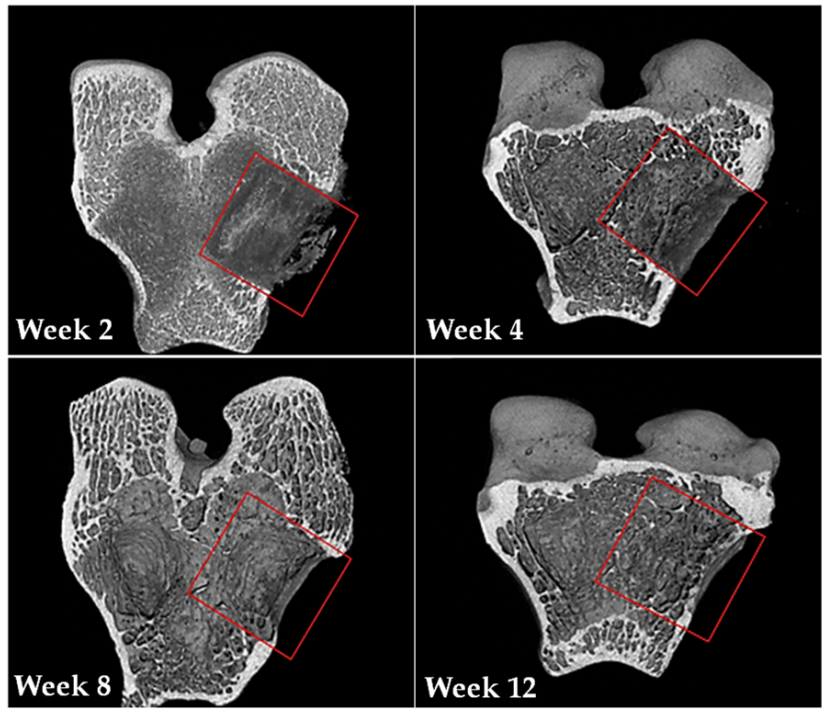

Figure 2. Micro-computed tomographic ( $\mu$-CT images) showing the surgical area and the healing area of (a) blank, (b) control, and (c) $\alpha$-CSH samples at each time point. 
Figure 3 represents the BMD in the defect calculated by $\mu$-CT scanning. It was seen that the density was equally increased with healing duration in each group. Apparently, the mineral density did not reveal any abnormality. Thus, the mineral can be deposited well in every animal after different applications. Figure 4 displays new bone volume in the defects measured from $\mu-C T$ scanning. At an early stage, in weeks 2 and 4, the new bone volume was lower than $10 \%$ in all treatment groups. Further, after 8 weeks, the new bone volume in defects increased more in the $\alpha$-CSH group than other groups. At the final observation at 12 weeks, the tissue remodeling by $\alpha$-CSH group had decreased the new bone volume, yet in other groups this increased at the same time as regular mineral density (Figure 3). This unique phenomenon could be explained due to the tissue remodeling process that caused the dense callus to be withdrawn in $\alpha$-CSH but not in blank and control material. The general concept of fracture healing can be described in four overlapping stages including hematoma formation, bone repair, which is divided into fibro-cartilaginous callus formation and bony callus formation, and bone remodeling. These stages occur at different times, with different cellular involvement, and different meanings [37,38]. Looking further into the process of bone remodeling, in this study, at 12 weeks after the implantation, we suggest that the $\alpha-\mathrm{CSH}$ group had entered the hard callus resorption step and begun to calcify into a new bone [39]. In this step, the defect area had lower callus volumes since the bone matrix and bone mineral was digested [40-42].

It is well known that calcium sulfate behaves like an osteoconductive matrix facilitating the structural framework to allow the growth of osteogenic cells and blood vessels into the defect area $[43,44]$. Some studies have verified that calcium sulfate hemihydrate promotes bone regeneration by generating bioactive and osteoconductive bone scaffolds [44,45]. As the calcium sulfate is resorbed, it acts as a main calcium source which is crucial throughout mineralization in progressive bone remodeling $[17,25]$. Local bone mineralization is related to the osteoinductive property of calcium sulfate [45], while the bone mineralization results from a local $\mathrm{pH}$ reduction which subsequently renders the release of osteoinductive molecules in the bone matrix inducing the healing process $[45,46]$.

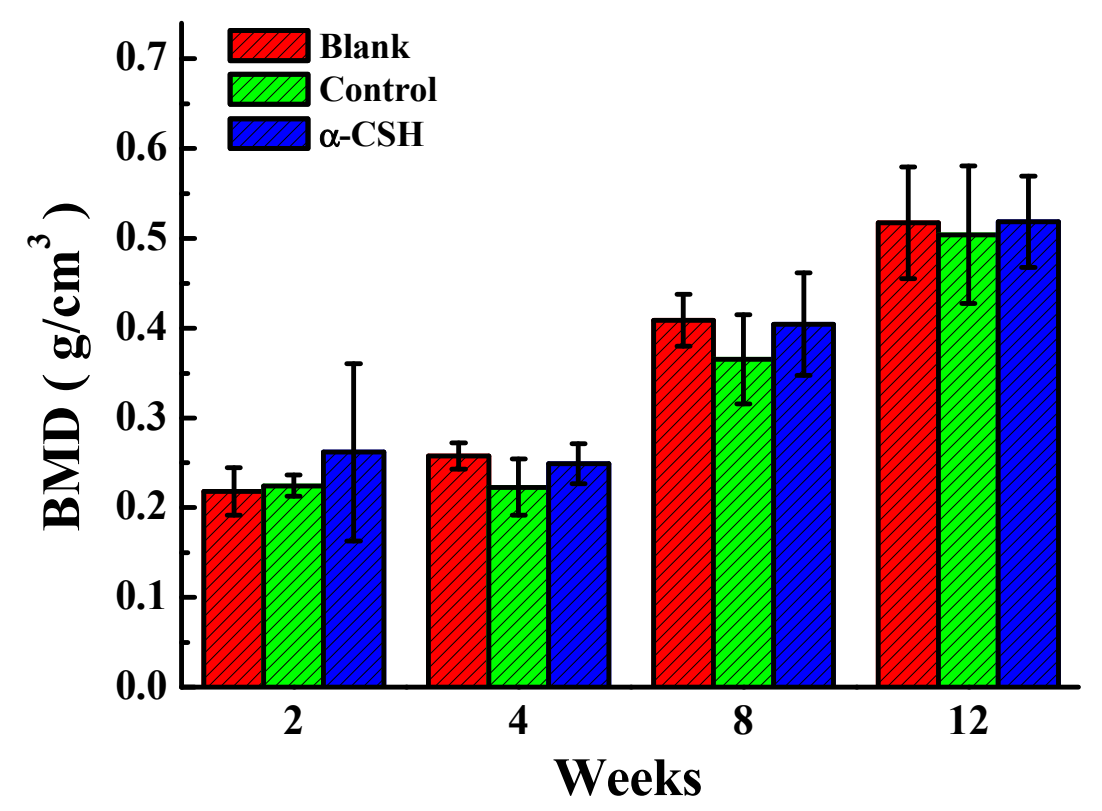

Figure 3. Bone mineral density (BMD) measured by $\mu$-CT evaluation at $2,4,8$, and 12 weeks after treatment. $(p>0.05)$. 


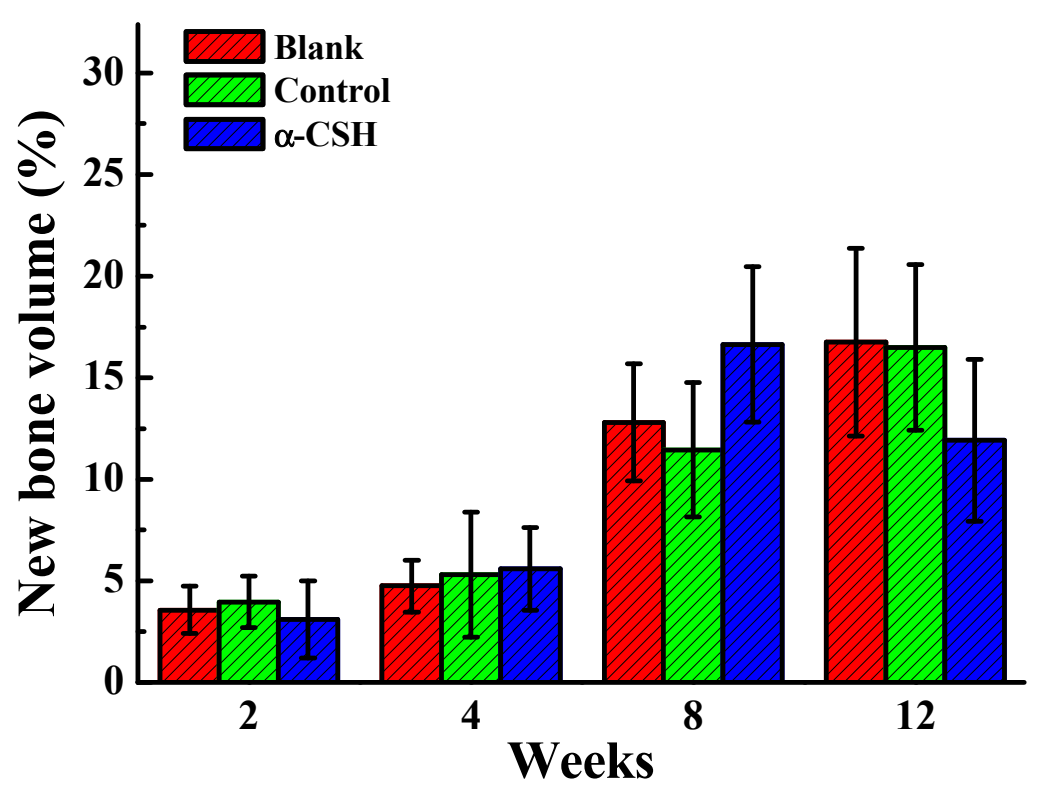

Figure 4. Bone volume percentage in artificially-created defects from $\mu$-CT evaluation at 2, 4, 8, and 12 weeks after treatment. $(p>0.05)$.

\subsection{Degradation Properties of the Implanted Materials}

In the present study, another measurement from $\mu$-CT scanning was focused on the implant residue after surgery. As presented in Figure 5, in both the control and $\alpha-\mathrm{CSH}$ groups this was reduced at a similar rate ( $87 \%$ at 4 weeks and $47 \sim 50 \%$ at 8 weeks). However, in the $\alpha$-CSH group it reduced more at 12 weeks (21\% remained), whereas in the control material, $38 \%$ residues remained in the defects. The resorption rate of calcium sulfate has been a concern for more than a century [43]. The osteoconduction of bone substitute requires the material to possess a resorption rate identical to that of new bone formation [47]. In fact, some authors have criticized the speed of resorption of calcium sulfate which happens before the new bone ingrowth is formed $[2,7,11,17,21]$. However, this characteristic depends not only on the chemical composition of materials, but also on the processing methods used to prepare, sterilize, and store the material [19]. Besides, other criteria are also paramount such as the location and size of the defect, chosen model, surface area per unit volume, scaffold dimensions, and porosity [48]. Due to the current advancements in the calcium sulfate formulation as a bone graft substitute, the resorption rate of calcium sulfate has been improved and is parallel to that of the new bone growth $[29,43]$. It was found that the contained defect was completely filled in the $\alpha$-CSH group without any issue regarding material resorption. Underlining this result, a previous study found the resorption rate of the calcium sulfate is consistent with that of bone ingrowth [47]. Von Rechenberg et al. [48] also demonstrated that calcium sulfate exhibited rapid cement resorption yet still presented decent fresh bone formation as compared with other different types of cement implanted into the bone defect.

In this study, considering the limited number of sample sizes, no significant differences were observed in BMD, new bone volume, or degradation rate (RMVF) between $\alpha-\mathrm{CSH}$, control, and blank groups. Nevertheless, from the measured average values of BMD and new bone volume at 8 and 12 weeks, it was seen that the $\alpha$-CSH group exhibited a tendency to have better progress in tissue remodeling compared to other groups. Accordingly, the innovative $\alpha$-CSH bioceramic may have great potential as a proper option for autogenous bone graft in managing bone defects and lesions. 


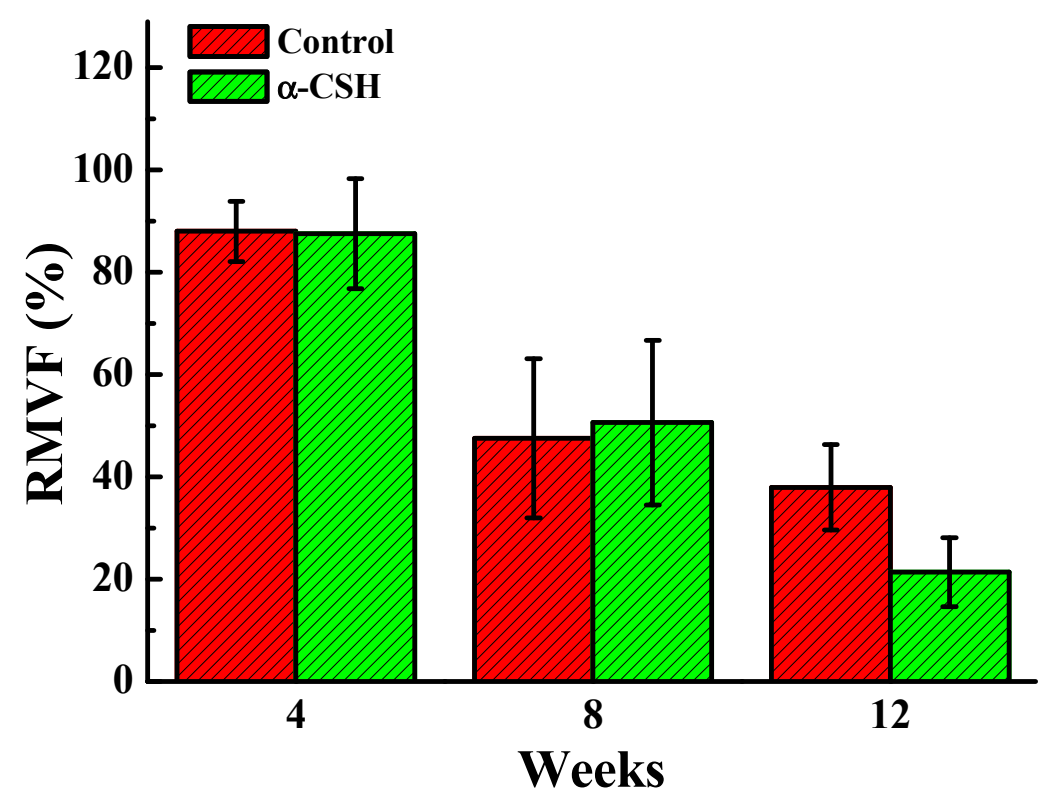

Figure 5. Material volume was calculated by $\mu$-CT scanning in defects at 2, 4, 8, and 12 weeks after implantation of $\alpha-\mathrm{CSH}$ and control material. The degradation at 4 and 8 weeks was similar between control material and $\alpha-\mathrm{CSH}$. At last observation, the $\alpha-\mathrm{CSH}$ reduced more than the control material. $(p>0.05)$.

\subsection{Bone Regeneration Characteristics of the Implanted Materials}

The individual histopathological evaluations are presented in Figures 6-9. At the 2-week observation, the process of new bone formation (ossification) was negative for every group (Figure 6). At the 4-week observation, the ossification was initialized in every group. The defects in the blank group were filled with fibrinous connective tissue with a very limited osseous fragment (Figure 7a). In the $\alpha-\mathrm{CSH}$ and control groups, the majority of tissue was branched, prosperous trabecular bone, and accompanied by fibrinous connective tissue and adipose tissues (Figure $7 \mathrm{~b}, \mathrm{c}$ ). Figure 8 illustrates the 8-week observation of the defect. It was found that the ossification in the $\alpha$-CSH group was decreased (Figure 8c) but similar to the control group (Figure 8b). At this stage, the tissue remodeling was in progress, and the new bone was annealed to the lamellar bone with bone marrow and adipose tissue infiltration. Twelve weeks after implantation, original structure was not restored in the blank group (only a small amount of new bone formation) (Figure 9a). On the contrary, bone in the control and $\alpha-\mathrm{CSH}$ groups was repaired with intact lamellar bone and bone marrow tissues (Figure 9b,c), while the $\alpha$-CSH group exhibited more regenerated bone tissues than that of the control group. This feature demonstrated that $\alpha$-CSH may have a promising potential to promote bone healing and regeneration after implantation.

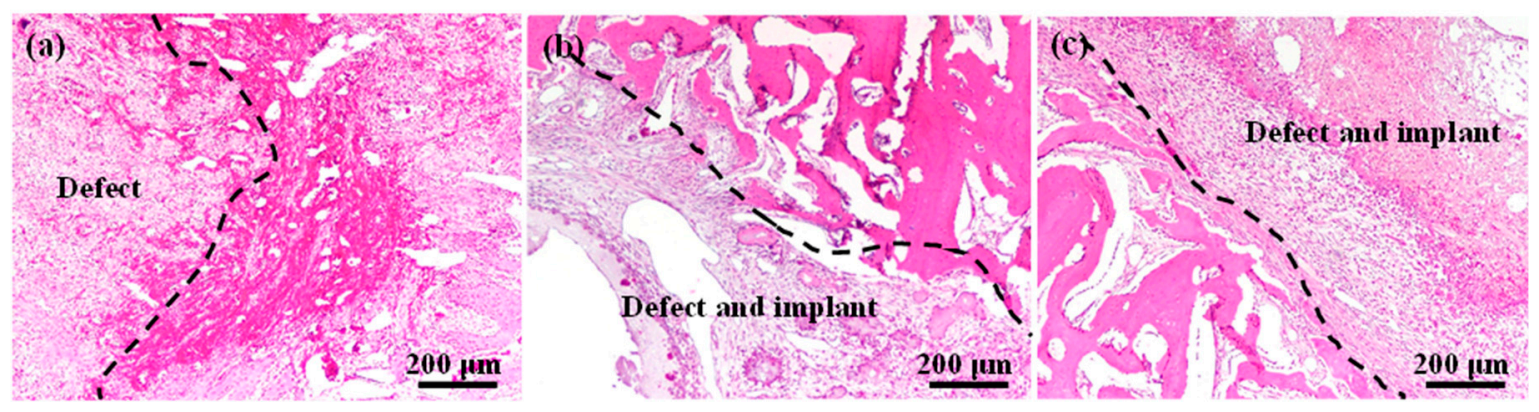

Figure 6. Images of hematoxylin and eosin (H\&E)-stained bone tissue 2 weeks after implantation: (a) blank, (b) control, and (c) $\alpha$-CSH samples. 

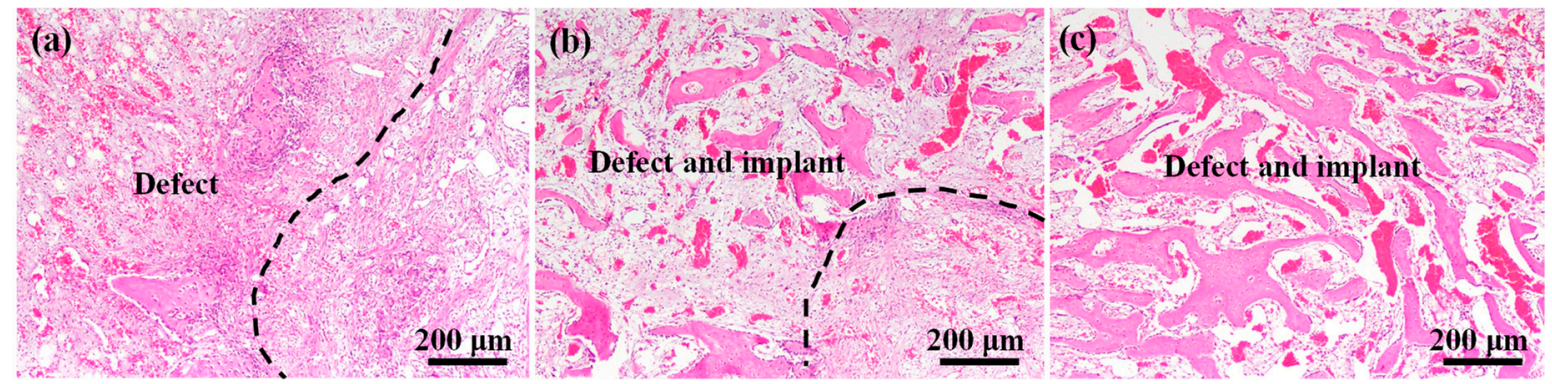

Figure 7. Images of H\&E-stained bone tissue 4 weeks after implantation: (a) blank, (b) control, and (c) $\alpha$-CSH samples.

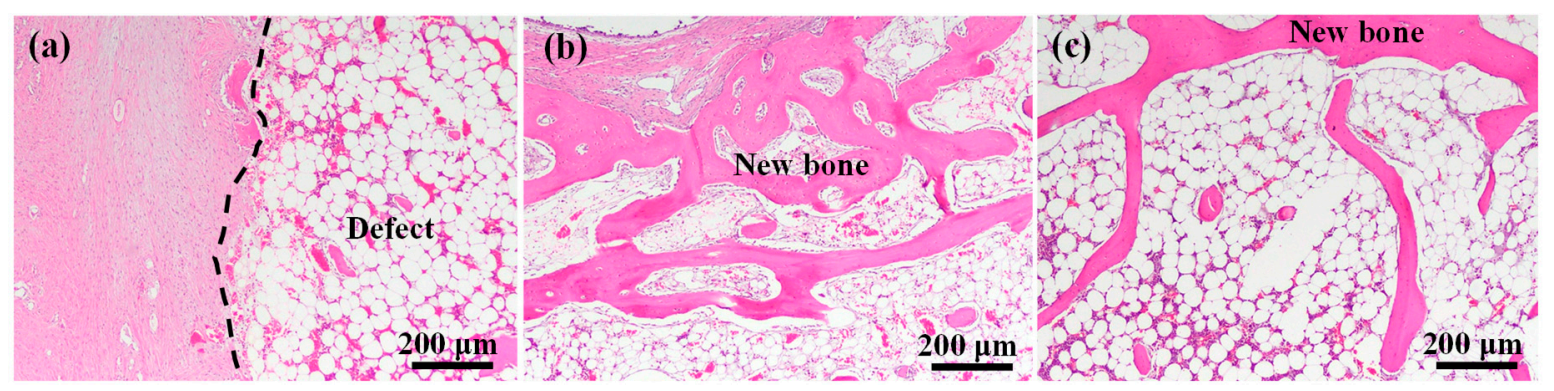

Figure 8. Images of H\&E-stained bone tissue 8 weeks after implantation: (a) blank, (b) control, and (c) $\alpha-\mathrm{CSH}$ samples.
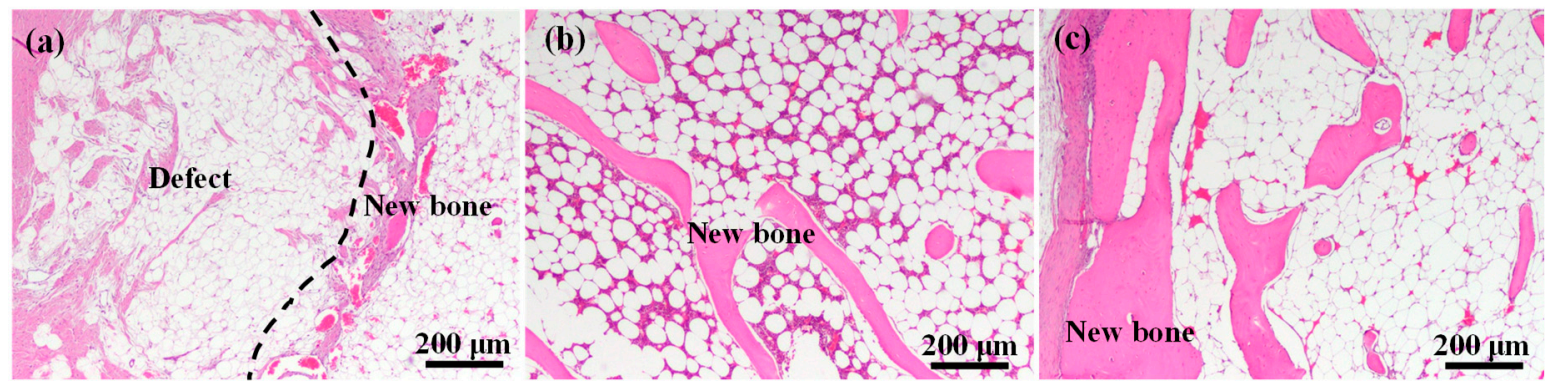

Figure 9. Images of H\&E-stained bone tissue 12 weeks after implantation: (a) blank, (b) control, and (c) $\alpha$-CSH samples.

Calcium sulfate has been recommended for use in the management of osseous defects after curettage of osteomyelitis, benign lesion, and trauma [45]. A high bone formation cloud has also been discovered in previous studies which found that calcium sulfate produces significantly more new bone formation and is completely effective in preserving alveolar bone in post-extraction ridge dimensions [46,47]. The new bone mineralization rate of calcium sulfate is similar to the rate of autograft material leading to its promising application in clinical practice [49]. In our previous study [27], the innovative $\alpha-\mathrm{CSH}$ with uniform and specific crystal structure had more water absorption ability in a dehydrated state for setting [50]. The rapid setting causes the proteins and growth factors in blood to be quickly absorbed into the bone defect area with implanted $\alpha-\mathrm{CSH}$ [35], hence offering enough nutrition for the osteoblasts to promote the formation of angiogenesis. In addition, when calcium sulfate is resorbed, it serves as a concentrated source of calcium, which is needed during mineralization in active bone remodeling as calcium ions play an impartment role in offering osteoblasts for bone formation [45]. Therefore, the analysis results have proved the potential to enhance in vivo biocompatibility of the $\alpha$-CSH group in the rabbit model. As stated above, the microwave-synthesized innovative $\alpha$-CSH bioceramic is believed to possess superior bone healing and regeneration ability for clinical applications. However, future tests will require larger sample sizes as well as larger animals such as 
pig or beagle models to get a statistical difference and to strengthen the present findings of the potential of the innovative $\alpha$-CSH bioceramic as a bone substitute in clinical applications.

\section{Conclusions}

Under the current circumstance of this study, the $\alpha$-CSH was non-irritant at each observational period when compared to the other two treatments. The ossification feature in the $\alpha-\mathrm{CSH}$ and control groups was better than the blank group and restored their original architectural structure with typical lamellar bone evolving at the host bone-implant margin while only a small amount of new bone was noticed in the blank group. These results demonstrate that no safety hazard concern should be announced in this study and the $\alpha-\mathrm{CSH}$ will generate a similar effect to the control material, indicated with acceptable degradation rate and better healing progress. Hence, the innovative $\alpha$-CSH bioceramic synthesized from the microwave-irradiation technique is worthwhile to be used as a bone graft substitute in clinical applications.

Author Contributions: Investigation, P.-J.H.; methodology, B.-H.H.; supervision; H.-H.C. and T.-S.Y.; writing-original draft, K.-L.O.; writing-review and editing, C.-F.H. and T.U. All authors have read and agreed to the published version of the manuscript.

Funding: This research received no external funding.

Conflicts of Interest: The authors report no conflict of interest in this work.

\section{References}

1. Smrke, D.; Roman, P.; Veselko, M.; Gubi, B. Treatment of bone defects-allogenic platelet gel and autologous bone technique. In Regenerative Medicine and Tissue Engineering; IntechOpen: London, UK, 2013.

2. Xiang, H.; Wang, Y.; Chang, H.; Yang, S.; Tu, M.; Zhang, X.; Yu, B. Cerium-containing $\alpha$-calcium sulfate hemihydrate bone substitute promotes osteogenesis. J. Biomater. Appl. 2019, 34, 250-260. [CrossRef] [PubMed]

3. De Grado, G.F.; Keller, L.; Idoux-Gillet, Y.; Wagner, Q.; Musset, A.-M.; Benkirane-Jessel, N.; Bornert, F.; Offner, D. Bone substitutes: A review of their characteristics, clinical use, and perspectives for large bone defects management. J. Tissue Eng. 2018, 9. [CrossRef]

4. Chen, Y.; Zhou, Y.; Yang, S.; Li, J.J.; Li, X.; Ma, Y.; Hou, Y.; Jiang, N.; Xu, C.; Zhang, S.; et al. Novel bone substitute composed of chitosan and strontium-doped $\alpha$-calcium sulfate hemihydrate: Fabrication, characterisation and evaluation of biocompatibility. Mater. Sci. Eng. C 2016, 66, 84-91. [CrossRef] [PubMed]

5. Calori, G.M.; Mazza, E.; Colombo, M.; Ripamonti, C. The use of bone-graft substitutes in large bone defects: Any specific needs? Injury 2011, 42, S56-S63. [CrossRef] [PubMed]

6. Liu, Z.; Yu, Z.; Chang, H.; Wang, Y.; Xiang, H.; Zhang, X.; Yu, B. Strontium-containing $\alpha$-calcium sulfate hemihydrate promotes bone repair via the TGF- $\beta /$ Smad signaling pathway. Mol. Med. Rep. 2019, 20, 3555-3564. [CrossRef] [PubMed]

7. Pförringer, D.; Harrasser, N.; Mühlhofer, H.; Kiokekli, M.; Stemberger, A.; Van Griensven, M.; Lucke, M.; Burgkart, R.; Obermeier, A. Osteoinduction and -conduction through absorbable bone substitute materials based on calcium sulfate: In vivo biological behavior in a rabbit model. J. Mater. Sci. Mater. Electron. 2018, 29, 17. [CrossRef]

8. Leventis, M.; Fairbairn, P.; Mangham, C.; Galanos, A.; Vasiliadis, O.; Papavasileiou, D.; Horowitz, R. Bone Healing in Rabbit Calvaria Defects Using a Synthetic Bone Substitute: A Histological and Micro-CT Comparative Study. Materials 2018, 11, 2004. [CrossRef]

9. Sánchez-Garcés, M.Á.; Camps-Font, O.; Escoda-Francolí, J.; Muñoz-Guzón, F.; Toledano-Serrabona, J.; Gay-Escoda, C. Short time guided bone regeneration using beta-tricalcium phosphate with and without fibronectin-An experimental study in rats. Medicina Oral Patología Oral Cirugia Bucal 2020. [CrossRef]

10. Yamada, M.; Egusa, H. Current bone substitutes for implant dentistry. J. Prosthodont. Res. 2018, 62, 152-161. [CrossRef]

11. Sohn, H.-S.; Oh, J.-K. Review of bone graft and bone substitutes with an emphasis on fracture surgeries. Biomater. Res. 2019, 23, 9. [CrossRef] 
12. Auston, D.A.; Feibert, M.; Craig, T.; Damron, T. Unexpected radiographic lucency following grafting of bone defects with calcium sulfate/tricalcium phosphate bone substitute. Skelet. Radiol. 2015, 44, 1453-1459. [CrossRef]

13. Lobb, D.C.; DeGeorge, B.R.; Chhabra, A.B. Bone Graft Substitutes: Current Concepts and Future Expectations. J. Hand Surg. 2019, 44, 497-505.e2. [CrossRef] [PubMed]

14. Rolvien, T.; Barbeck, M.; Wenisch, S.; Amling, M.; Krause, M. Cellular Mechanisms Responsible for Success and Failure of Bone Substitute Materials. Int. J. Mol. Sci. 2018, 19, 2893. [CrossRef] [PubMed]

15. Ho, M.-L.; Fu, Y.-C.; Wang, Y.-H.; Chen, C.-H.; Wang, C.-K.; Wang, G.-J. Combination of calcium sulfate and simvastatin-controlled release microspheres enhances bone repair in critical-sized rat calvarial bone defects. Int. J. Nanomed. 2015, 10, 7231-7240. [CrossRef] [PubMed]

16. Yang, S.; Wang, L.; Feng, S.; Yang, Q.; Yu, B.; Tu, M. Enhanced bone formation by strontium modified calcium sulfate hemihydrate in ovariectomized rat critical-size calvarial defects. Biomed. Mater. 2017, 12, 035004. [CrossRef]

17. Pei, F.; Li, Y.; Yang, J.; Yang, X.; Huang, Q.; Shen, B. Evaluation of a biodegradable graft substitute in rabbit bone defect model. Indian J. Orthop. 2012, 46, 266-273. [CrossRef] [PubMed]

18. Shih, T.C.; Chang, W.J.; Yang, J.C.; Feng, S.W.; Lin, C.T.; Teng, N.C. In vivo evaluation of resorbable bone graft substitutes in mandibular sockets of the beagle. J. Biomed. Mater. Res. Part A 2012, 100, 2726-2731. [CrossRef]

19. Kuo, T.-F.; Lee, S.-Y.; Wu, H.-D.; Poma, M.; Wu, Y.-W.; Yang, J.-C. An in vivo swine study for xeno-grafts of calcium sulfate-based bone grafts with human dental pulp stem cells (hDPSCs). Mater. Sci. Eng. C 2015, 50, 19-23. [CrossRef]

20. Yang, G.; Liu, J.; Li, F.; Pan, Z.; Ni, X.; Shen, Y.; Xu, H.; Huang, Q. Bioactive calcium sulfate/magnesium phosphate cement for bone substitute applications. Mater. Sci. Eng. C 2014, 35, 70-76. [CrossRef]

21. Meng, Z.L.; Wu, Z.Q.; Shen, B.X.; Li, H.B.; Bian, Y.Y.; Zeng, D.L.; Fu, J.; Peng, L. Reconstruction of large segmental bone defects in rabbit using the Masquelet technique with $\alpha$-calcium sulfate hemihydrate. J. Orthop. Surg. Res. 2019, 14, 1-12. [CrossRef]

22. Campana, V.; Milano, G.; Pagano, E.; Barba, M.; Cicione, C.; Salonna, G.; Lattanzi, W.; Logroscino, G. Bone substitutes in orthopaedic surgery: From basic science to clinical practice. J. Mater. Sci. Mater. Electron. 2014, 25, 2445-2461. [CrossRef]

23. Orsini, G.; Ricci, J.; Scarano, A.; Pecora, G.; Petrone, G.; Iezzi, G.; Piattelli, A. Bone-defect healing with calcium-sulfate particles and cement: An experimental study in rabbit. J. Biomed. Mater. Res. 2004, 68, 199-208. [CrossRef] [PubMed]

24. Guarnieri, R.; Grassi, R.; Ripari, M.; Pecora, G. Maxillary sinus augmentation using granular calcium sulfate (surgiplaster sinus): Radiographic and histologic study at 2 years. Int. J. Periodontics Restor. Dent. 2006, 26, 79-85.

25. Bagoff, R.; Mamidwar, S.; Chesnoiu-Matei, I.; Ricci, J.L.; Alexander, H.; Tovar, N. Socket Preservation and Sinus Augmentation Using a Medical Grade Calcium Sulfate Hemihydrate and Mineralized Irradiated Cancellous Bone Allograft Composite. J. Oral Implant. 2013, 39, 363-371. [CrossRef]

26. Guarnieri, R.; Pecora, G.; Fini, M.; Aldini, N.N.; Giardino, R.; Orsini, G.; Piattelli, A. Medical Grade Calcium Sulfate Hemihydrate in Healing of Human Extraction Sockets: Clinical and Histological Observations at 3 Months. J. Periodontol. 2004, 75, 902-908. [CrossRef] [PubMed]

27. Hsu, H.-J.; Waris, R.A.; Ruslin, M.; Lin, Y.-H.; Chen, C.-S.; Ou, K.-L. An innovative $\alpha$-calcium sulfate hemihydrate bioceramic as a potential bone graft substitute. J. Am. Ceram. Soc. 2017, 101, 419-427. [CrossRef]

28. Zhang, S.; Yang, K.; Cui, F.; Jiang, Y.; E, L.; Xu, B.-H.; Liu, H. A Novel Injectable Magnesium/Calcium Sulfate Hemihydrate Composite Cement for Bone Regeneration. BioMed Res. Int. 2015, 2015, 297437. [CrossRef]

29. Fu, L.; Xia, W.; Mellgren, T.; Moge, M.; Engqvist, H. Preparation of High Percentage? Calcium Sulfate Hemihydrate via a Hydrothermal Method. J. Biomater. Nanobiotechnol. 2017, 8, 36-49. [CrossRef]

30. Combe, E.C.; Smith, D.C. Studies on the preparation of calcium sulphate hemihydrate by an autoclave process. J. Appl. Chem. 2007, 18, 307-312. [CrossRef]

31. Mu, X.; Zhu, G.; Li, X.; Li, S.; Gong, X.; Li, H.; Sun, G. Effects of impurities on CaSO(4) crystallization in the $\mathrm{Ca}(\mathrm{H}(2) \mathrm{PO}(4))(2)-\mathrm{H}(2) \mathrm{SO}(4)-\mathrm{H}(3) \mathrm{PO}(4)-\mathrm{H}(2) \mathrm{O}$ system. ACS Omega 2019, 4, 12702-12710. [CrossRef]

32. Ye, Q.; Guan, B.; Lou, W.; Yang, L.; Kong, B. Effect of particle size distribution on the hydration and compressive strength development of $\alpha$-calcium sulfate hemihydrate paste. Powder Technol. 2011, 207, 208-214. [CrossRef] 
33. Teoreanu, I.; Preda, M.; Melinescu, A. Synthesis and characterization of hydroxyapatite by microwave heating using $\mathrm{CaSO}_{4} \cdot 2 \mathrm{H}_{2} \mathrm{O}$ and $\mathrm{Ca}(\mathrm{OH})_{2}$ as calcium source. J. Mater. Sci. Mater. Med. 2008, 19, 517-523. [CrossRef]

34. Chen, Z.; Liu, H.; Liu, X.; Lian, X.; Guo, Z.; Jiang, H.-J.; Cui, F.-Z. Improved workability of injectable calcium sulfate bone cement by regulation of self-setting properties. Mater. Sci. Eng. C 2013, 33, 1048-1053. [CrossRef] [PubMed]

35. Guan, B.; Ye, Q.; Zhang, J.; Lou, W.; Wu, Z. Interaction between $\alpha$-calcium sulfate hemihydrate and superplasticizer from the point of adsorption characteristics, hydration and hardening process. Cem. Concr. Res. 2010, 40, 253-259. [CrossRef]

36. Saghiri, M.A.; Asatourian, A.; Garcia-Godoy, F.; Sheibani, N. The role of angiogenesis in implant dentistry part II: The effect of bone-grafting and barrier membrane materials on angiogenesis. Med. Oral Patol. Oral Cir. Bucal 2016, 21, e526-e537. [CrossRef] [PubMed]

37. Schindeler, A.; McDonald, M.M.; Bokko, P.; Little, D.G. Bone remodeling during fracture repair: The cellular picture. Semin. Cell Dev. Biol. 2008, 19, 459-466. [CrossRef] [PubMed]

38. Rentsch, C.; Schneiders, W.; Manthey, S.; Rentsch, B.; Rammelt, S. Comprehensive histological evaluation of bone implants. Biomatter 2014, 4, e27993. [CrossRef]

39. Marsell, R.; Einhorn, T. The biology of fracture healing. Injury 2011, 42, 551-555. [CrossRef]

40. Yoo, Y.-M.; Lee, M.-H.; Park, J.H.; Seo, D.-H.; Lee, S.; Jung, B.; Kim, H.-S.; Bae, K. Decreased Bone Volume and Bone Mineral Density in the Tibial Trabecular Bone Is Associated with Per2 Gene by 405 nm Laser Stimulation. Int. J. Mol. Sci. 2015, 16, 27401-27410. [CrossRef]

41. Dimitriou, R.; Jones, E.; McGonagle, D.; Giannoudis, P.V. Bone regeneration: Current concepts and future directions. BMC Med. 2011, 9, 66. [CrossRef]

42. Fernández-Tresguerres-Hernández-Gil, I.; Alobera-Gracia, M.A.; Del-Canto-Pingarrón, M.; Blanco-Jerez, L. Physiological bases of bone regeneration II. The remodeling process. Med. Oral Patol. Oral Cir. Bucal 2006, 11, E151-E157. [PubMed]

43. Kim, J.H.; Oh, J.H.; Han, I.; Kim, H.-S.; Chung, S.W. Grafting Using Injectable Calcium Sulfate in Bone Tumor Surgery: Comparison with Demineralized Bone Matrix-based Grafting. Clin. Orthop. Surg. 2011, 3, $191-201$. [CrossRef]

44. Strocchi, R.; Orsini, G.; Iezzi, G.; Scarano, A.; Rubini, C.; Pecora, G.; Piattelli, A. Bone regeneration with calcium sulfate: Evidence for increased angiogenesis in rabbits. J. Oral Implantol. 2002, 28, 273-278. [CrossRef]

45. Kumar, Y.; Nalini, K.; Menon, J.; Patro, D.K.; Banerji, B. Calcium Sulfate as Bone Graft Substitute in the Treatment of Osseous Bone Defects, A Prospective Study. J. Clin. Diagn. Res. 2013, 7, 2926-2928. [CrossRef] [PubMed]

46. Ruga, E.; Gallesio, C.; Chiusa, L.; Boffano, P. Clinical and Histologic Outcomes of Calcium Sulfate in the Treatment of Postextraction Sockets. J. Craniofacial Surg. 2011, 22, 494-498. [CrossRef] [PubMed]

47. Toloue, S.M.; Chesnoiu-Matei, I.; Blanchard, S.B. A Clinical and Histomorphometric Study of Calcium Sulfate Compared with Freeze-Dried Bone Allograft for Alveolar Ridge Preservation. J. Periodontol. 2012, 83, 847-855. [CrossRef] [PubMed]

48. Cortez, P.P.; Silva, M.A.; Santos, M.; Armada-da-Silva, P.; Afonso, A.; Lopes, M.A.; Santos, J.D.; Maurício, A.C. A glass-reinforced hydroxyapatite and surgical-grade calcium sulfate for bone regeneration: In vivo biological behavior in a sheep model. J. Biomater. Appl. 2012, 27, 201-217. [CrossRef]

49. Von Rechenberg, B.; Génot, O.R.; Nuss, K.; Galuppo, L.; Fulmer, M.; Jacobson, E.; Kronen, P.; Zlinszky, K.; Auer, J.A. Evaluation of four biodegradable, injectable bone cements in an experimental drill hole model in sheep. Eur. J. Pharm. Biopharm. 2013, 85, 130-138. [CrossRef]

50. Mao, K.; Zhou, F.; Cui, F.; Li, J.; Hou, X.; Li, P.; Du, M.; Liang, M.; Wang, Y. Preparation and properties of $\alpha$-calcium sulphate hemihydrate and $\beta$-tricalcium phosphate bone substitute. Bio-Med. Mater. Eng. 2013, 23, 197-210. [CrossRef]

(C) 2020 by the authors. Licensee MDPI, Basel, Switzerland. This article is an open access article distributed under the terms and conditions of the Creative Commons Attribution (CC BY) license (http://creativecommons.org/licenses/by/4.0/). 